\title{
Horizontal-Vertical-Rocking Coupled Response Analysis of Vertical Seismic Isolated Structure under Near-Fault Earthquakes
}

\author{
Dewen Liu, ${ }^{1}$ Yafei Zhang, ${ }^{1}$ Sitong Fang, ${ }^{1}$ and Yang Liu $\mathbb{D}^{2}$ \\ ${ }^{1}$ College of Civil Engineering, Southwest Forestry University, Kunming, China \\ ${ }^{2}$ College of Civil Engineering, Tongji University, Shanghai 200092, China \\ Correspondence should be addressed to Yang Liu; winner5299@163.com
}

Received 31 December 2019; Revised 2 June 2020; Accepted 29 June 2020; Published 23 July 2020

Academic Editor: Lutz Auersch

Copyright (c) 2020 Dewen Liu et al. This is an open access article distributed under the Creative Commons Attribution License, which permits unrestricted use, distribution, and reproduction in any medium, provided the original work is properly cited.

For vertical isolated structures with excessive vertical eccentricity for mass and vertical stiffness, horizontal-vertical-rocking response needs to be better understood for vertical isolated structures located in near-fault areas, where long-period velocity pulse can be produced. In this study, a seismic isolation system including quasizero stiffness (QZS) and vertical damper (VD) is used to control near-fault (NF) vertical earthquakes. The responses of horizontal-vertical-rocking coupling base-isolated structure including quasizero stiffness (QZS) and vertical damper (VD) subjected to NF horizontal and vertical ground motions are investigated. Nonlinear dynamic analyses are conducted to study the effects of essential parameters such as isolation system eccentricity, static equilibrium position, vertical isolation period, and vertical damping ratio on seismic responses of vertical isolated structure. It is found that increasing vertical period and damping ratio causes the vertical isolated structures to behave well in reducing rocking responses of structure. The effect of horizontal-vertical-rocking coupling on vertical seismic isolation efficiency is insignificant. The vertical seismic isolation remains effective as compared to the system supported on rubber bearings. The vertical damping can significantly control the vertical displacement and rocking moment.

\section{Introduction}

Seismic isolations are one of the most effective mitigation strategies implemented to protect the structure from seismic damage. Modern isolation techniques have been successfully tested and implemented in practice. However, most buildings with seismic isolation devices are not designed to reduce the vertical component of earthquake ground motions. Shaking table tests have testified that rubber base isolation system could significantly amplify vertical accelerations [1]. Especially for the building under the near-fault (NF) vertical earthquakes, the structural and nonstructural damage was significant [2].

To control vertical seismic effects, several researchers have developed some devices to mitigate earthquakes, such as the low shape factor (LSF) elastomeric bearings [3] and air springs consisting of cylinders filled with nitrogen gas $[4,5]$. However, these approaches are so costly and hence not likely to be widely applied. Besides, in order to achieve the seismic isolation effect, a longer vertical isolation period implies a lower vertical flexible, which will lead to larger static displacement. This hinders the development of vertical seismic isolation systems. In recent years, quasizero stiffness (QZS) systems have been developed to overcome this disadvantage $[6,7]$. Nevertheless, the new approaches are applied for the isolation of mechanical engineering only, and very limited research studies focus on vertical seismic isolation considering QZS using damper.

Numerous research studies have reported that base isolation systems have a significant effect on decreasing torsional response of structures during severe earthquakes by providing flexibility and energy dissipation capacity [8-10]. However, report and research work on rocking problem that results from the vertical structure eccentricity between the center of mass $(\mathrm{CM})$ and the center of rigidity (CR) of vertical isolated structure have rarely been investigated.

In this study, the dynamic behavior of a building supported on vertical isolation bearings including quasizero stiffness (QZS) and vertical damper (VD) under horizontal and vertical ground motions has been investigated. Such a 
system has a horizontal eccentricity between the CM of the building and CR of supporting bearings. The important parameters affecting horizontal-vertical-rocking response have been identified. The effects of the static equilibrium position, vertical period, and eccentricity of the structure on the rocking responses and the isolation effectiveness for the isolated system with QZS and VD are analyzed. The main objectives of the study are (1) to examine the behavior of a horizontal-vertical-rocking coupled structure isolated with QZS and VD under NF ground motions; (2) to investigate the effectiveness of the vertical isolation using QZS and VD for a horizontal-vertical-rocking coupled structure under a set of important parametric variations.

\section{The Dynamic System of Vertical Seismic Isolated Structure Model Using QZS and VD}

Figure 1 shows the model of a seismic isolated structure with QZS and VD. The system consists of an isolation system, supported on an intermediate mass, together with a vertical stiffness, in parallel with two oblique springs with stiffness [6]. It is assumed that $h_{0}$ is static equilibrium position. Reference coordinate system of dynamic equilibrium equation is established at static equilibrium position $h_{0}$. The structure oscillation reaches the steady state around the static equilibrium position $h_{0}$. In Figure 1, the force-deflection characteristic for seismic isolated structures with QZS is given by

$$
F=2 k\left(L-\sqrt{a^{2}+\left(h_{0}-z\right)^{2}}\right) \frac{\left(h_{0}-z\right)}{\sqrt{a^{2}+\left(h_{0}-z\right)^{2}}}+k_{v} z \text {. }
$$

For the purpose of evaluating the horizontal-verticalrocking coupling effect of the isolation system, it is assumed that the isolated structure is entirely rigid. This assumption is valid provided that the nominal frequency of the isolation system is well separated from the natural frequency of the structure. Therefore, the isolated building on a grid of QZS bearings is idealized as a rigid block, which is supported on massless bearings. The rigid block has mass $m$ and moment of inertia $m r^{2}$ lumped at the geometric center. The idealized system has two degrees of freedom defined at CM of the rigid block as shown in Figure 2. The model degrees-of-freedom (DOFs) are vertical displacement $z$ and rotation $\theta$ of the block at its CM. The CM is located at the geometrical center of the building.

\section{Dynamic Equation of Motion for Seismic Input}

When the structure oscillation reaches the steady state around the static equilibrium position, the dynamic equilibrium can be established as

$$
\begin{aligned}
& m \ddot{z}+2 k\left[h_{0}-(z+e \theta)\right]\left(\frac{L}{\sqrt{a^{2}+\left[h_{0}-(z+e \theta)\right]^{2}}}-1\right) \\
& \quad+k_{v}(z+e \theta)+c_{v}(\dot{z}+e \dot{\theta})=-m \ddot{z}_{g}+m g .
\end{aligned}
$$

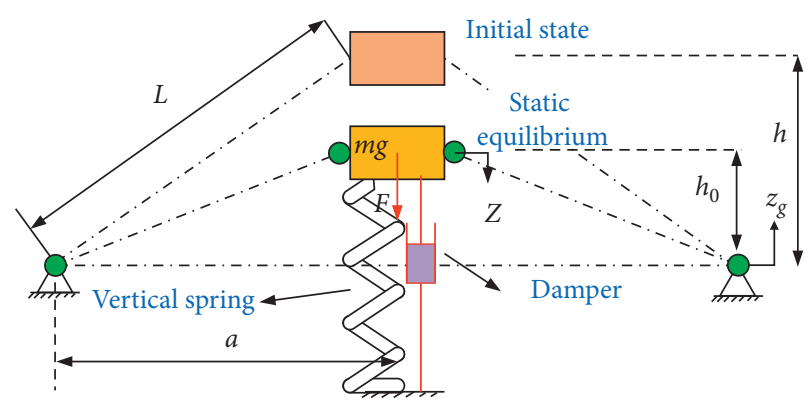

FIgURE 1: The dynamic analysis model of a QZS isolator at a static equilibrium position.

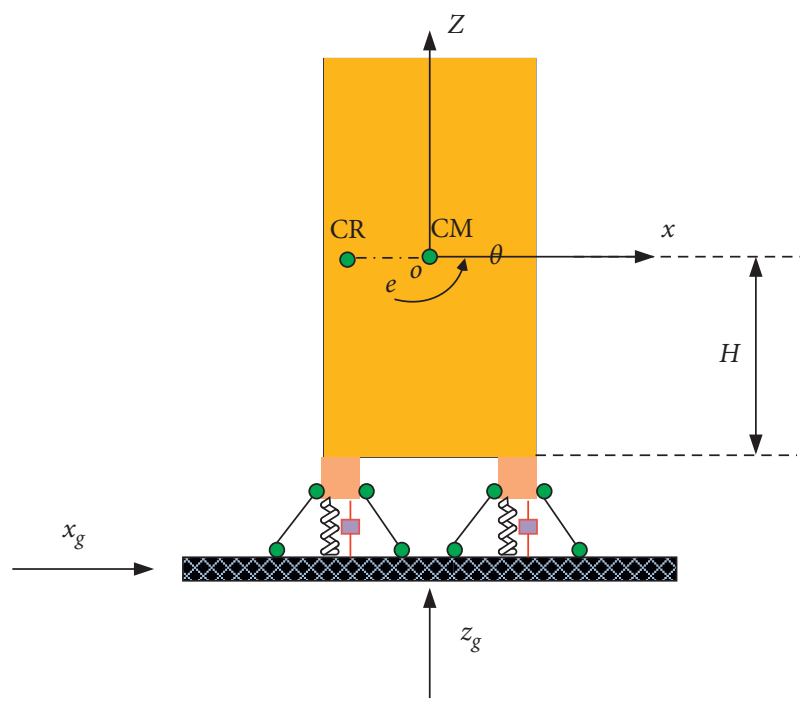

FIGURE 2: Vertical seismic isolated structure model using QZS and VD under horizontal and vertical ground motions.

$$
2 k\left(L-\sqrt{a^{2}+h_{0}^{2}}\right) \frac{h_{0}}{\sqrt{a^{2}+h_{0}^{2}}}=m g .
$$

Substituting (3) into (2) yields

$$
\begin{aligned}
& m \ddot{z}+2 k\left[h_{0}-(z+e \theta)\right]\left(\frac{L}{\sqrt{a^{2}+\left[h_{0}-(z+e \theta)\right]^{2}}}-1\right) \\
& -2 k h_{0}\left(\frac{L}{\sqrt{a^{2}+h_{0}^{2}}}-1\right)+k_{v}(z+e \theta)+c_{v}(\dot{z}+e \dot{\theta})=-m \ddot{z}_{g}, \\
& \ddot{z}+2 \omega_{v}^{2} \beta\left[h_{0}-(z+e \theta)\right]\left(\frac{L}{\sqrt{a^{2}+\left[h_{0}-(z+e \theta)\right]^{2}}}-1\right) \\
& -2 \omega_{v}^{2} \beta h_{0}\left(\frac{L}{\sqrt{a^{2}+h_{0}^{2}}}-1\right)+\omega_{v}^{2}(z+e \theta)+2 \omega \xi(\dot{z}+e \dot{\theta})=-\ddot{z}_{g} .
\end{aligned}
$$

The horizontal equilibrium equation is
In Figure 2, the static equilibrium equation is 


$$
m \ddot{x}+k_{h}\left(x+H_{0} \theta\right)+c_{h} \dot{x}=-m \ddot{x},
$$

which can be written as

$$
\ddot{x}+\omega_{h}^{2}\left(x+H_{0} \theta\right)+2 \omega_{h} \xi_{h} \dot{x}=-\ddot{x}_{g},
$$

where $\omega_{h}^{2}=k_{h} / m, \xi_{h}=c_{h} / 2 m \omega_{h}, T_{h}=2 \pi / \omega_{h}$.

The rocking equilibrium equation is

$$
\begin{aligned}
& J \ddot{\theta}+e\left\{2 k\left[h_{0}-(z+e \theta)\right]\left(\frac{L}{\sqrt{a^{2}+\left[h_{0}-(z+e \theta)\right]^{2}}}-1\right)\right. \\
& \left.-2 k h_{0}\left(\frac{L}{\sqrt{a^{2}+h_{0}^{2}}}-1\right)+k_{v}(z+e \theta)+c_{v}(\dot{z}+e \dot{\theta})\right\} \\
& +k_{h} H_{0}\left(x+H_{0} \theta\right)=0,
\end{aligned}
$$

which can be written as

$$
\begin{aligned}
& r^{2} \ddot{\theta}+e\left\{2 \omega_{v}^{2} \beta\left[h_{0}-(z+e \theta)\right]\left(\frac{L}{\sqrt{a^{2}+\left[h_{0}-(z+e \theta)\right]^{2}}}-1\right)\right. \\
& \left.-2 \omega_{v}^{2} \beta h_{0}\left(\frac{L}{\sqrt{a^{2}+h_{0}^{2}}}-1\right)+\omega_{v}^{2}(z+e \theta)+2 \omega \xi(\dot{z}+e \dot{\theta})\right\} \\
& +\omega_{h}^{2} H_{0}\left(x+H_{0} \theta\right)=0,
\end{aligned}
$$

where $r=\sqrt{\left(B^{2}+H^{2}\right) / 12}, \quad \omega^{2}=k_{v} / m, \quad \xi=c_{v} / 2 m \omega_{v}, \quad T=$ $2 \pi / \omega$.

The numerical procedure has been programmed by MATLAB software. To evaluate the performance of the system, the horizontal acceleration amplification coefficient and the vertical acceleration amplification coefficient are indexes to represent the isolation effect as follows:

$$
\operatorname{ACCX}=\frac{\max (|\ddot{x}|)}{A_{x}},
$$

where $A_{x}$ is the maximum seismic acceleration.

$$
\mathrm{ACCZ}=\frac{\max (|\ddot{x}|)}{A_{z}},
$$

where $A_{z}$ is the maximum seismic acceleration.

\section{Selection of NF Ground Motion Records}

Twenty different NF ground motions are selected to analyze horizontal-vertical-rocking coupled response of seismic isolated structure. Selection criteria for earthquake records are given as follows [11]:

(i) These motions cover a moment magnitude range from 6.0 to 7.6

(ii) The rupture distance (closest distance from site to fault rupture plane) ranges from 0 to $10 \mathrm{~km}$ (iii) Their shear-wave velocities at the uppermost $30 \mathrm{~m}$ $\left(v_{30}\right)$ soil profile are greater than $200 \mathrm{~m} / \mathrm{s}$

20 different earthquake records (Table 1) including horizontal and vertical components are used to examine the effects of the characteristics of the excitation on the seismic response of the vertical isolated building. Elastic response spectra for $5 \%$ critical damping generated with the vertical components of the recorded ground motions are presented in Figures 3 and 4. Also plotted in this figure is the average spectrum. The peak acceleration (PGA) corresponding to earthquakes of major levels is specified to be $0.4 \mathrm{~g}$.

\section{Seismic Response Analysis}

Seismic responses including ACCX, horizontal displacement $x$, ACCZ, vertical displacement $z$, rotation $\theta$, and rocking moment $T_{c r}$ of vertical seismic isolated structures with QZS and VD under NF horizontal and vertical earthquakes are conducted to analyze the isolation effects. The comprehensive influences of static equilibrium position $h_{0}$, vertical period, and damping ratio are investigated numerically. To evaluate the rocking responses for the isolated system with QZS and VD, the effects of rocking parameter (eccentricity ratio $e / r=0.00,0.10,0.15,0.20,0.25,0.30,0.35,0.40)$ on isolation efficiency are analyzed. The length of oblique spring is $L=0.5 \mathrm{~m}$. The resulting value of $\gamma$ is 0.87 . $B=9 \mathrm{~m}$, $H=27 \mathrm{~m}, H_{0}=12 \mathrm{~m} ; \xi_{h}=0.2$ and $T_{h}=2 \mathrm{~s}$. It is assumed that the mass reaches the position at $y=h_{0}$ which is a QZS position. In the case of QZS position, $\beta=3.36$. Parameter analysis uses mean values of 20 ground waves response results.

5.1. Seismic Response Spectra Results. Figure 5 shows the acceleration spectra of NF horizontal and vertical ground motions and acceleration response of vertical isolated structure $(\xi=5 \%)$. It can be seen that peak acceleration response spectra of vertical isolated structure $(\xi=5 \%)$ is less than the input NF wave. The corresponding vibration period of peak acceleration value for the input NF wave have been shifted to longer range due to the isolation effect of vertical isolated structure. It means that the vertical isolation system with QZS and VD can avoid resonance and resulting significant reduction of vertical responses.

5.2. Force-Deflection Results. The vertical displacement versus force response curve of the system without eccentricity and with eccentricity $(e / r=0.05)$ are shown in Figure $6\left(h_{0}=0.1 \mathrm{~m}\right)$. The force-displacement curves for both eccentricity and no eccentricity are observed to be unsymmetric about the $x$-axis. This occurs because compression deformation is larger than tension deformation. However, with the height of the static equilibrium position increasing, the deformation of the isolator decreases. Because of the dissipation energy of damper, the deformation of the isolator decreases. Moreover, displacement control effect of system with eccentricity is better than system without eccentricity. For the analyzed cases, the 
TABle 1: Near-fault pulse-like record data.

\begin{tabular}{|c|c|c|c|c|c|c|}
\hline No & Event & Station & Moment magnitude & $R_{\text {rup }}$ & Mechanism & $v_{30}$ \\
\hline 1 & Loma Prieta, USA, 1989 & Saratoga-Aloha Ave., CMP & 6.9 & 8.5 & Reverse & 380.89 \\
\hline 2 & Kocaeli, Turkey, 1999 & Izmit, IZT & 7.51 & 7.21 & Strike slip & 811.00 \\
\hline 3 & Chi-Chi, Taiwan, 1999 & TCU089 & 7.6 & 8.88 & Reverse & 671.52 \\
\hline 4 & Chi-Chi, Taiwan, 1999 & CHY080 & 7.6 & 2.69 & Reverse & 496.21 \\
\hline 5 & Chi-Chi, Taiwan, 1999 & TCU049 & 7.6 & 3.76 & Reverse & 487.27 \\
\hline 6 & Chi-Chi, Taiwan, 1999 & TCU051 & 7.6 & 7.64 & Reverse & 350.06 \\
\hline 7 & Chi-Chi, Taiwan, 1999 & TCU052 & 7.6 & 0.66 & Reverse & 579.1 \\
\hline 8 & Chi-Chi, Taiwan, 1999 & TCU068 & 7.6 & 0.32 & Reverse & 487.34 \\
\hline 9 & Chi-Chi, Taiwan, 1999 & TCU075 & 7.6 & 0.89 & Reverse & 573.02 \\
\hline 10 & Chi-Chi, Taiwan, 1999 & TCU076 & 7.6 & 2.74 & Reverse & 614.98 \\
\hline 11 & Imperial, Valley, 1979 & El Centro\#4 & 6.53 & 7.05 & Strike slip & 208.91 \\
\hline 12 & Imperial, Valley, 1979 & El Centro\#5 & 6.53 & 3.95 & Strike slip & 205.63 \\
\hline 13 & Imperial, Valley, 1979 & El Centro\#7 & 6.53 & 0.56 & Strike slip & 201.51 \\
\hline 14 & Imperial, Valley, 1979 & El Centro\#10 & 6.53 & 8.6 & Strike slip & 202.85 \\
\hline 15 & Imperial, Valley, 1979 & El centro differential array & 6.53 & 5.09 & Strike slip & 202.26 \\
\hline 16 & Loma Prieta, USA, 1989 & Los gatos-lexington dam & 6.9 & 5.02 & Reverse & 1070.32 \\
\hline 17 & Tabas, Iran, 1978 & Tabas & 7.35 & 2.05 & Reverse & 767.77 \\
\hline 18 & Northridge, USA, 1994 & LA dam & 6.7 & 5.92 & Reverse & 628.99 \\
\hline 19 & Northridge, USA, 1994 & Pacoima dam (upper left) & 6.7 & 7.01 & Reverse & 2016.33 \\
\hline 20 & Kobe, Japan, 1995 & KJMA & 6.9 & 0.96 & Strike slip & 312 \\
\hline
\end{tabular}

Table 1 is reproduced from Dewen Liu et al. 2018.

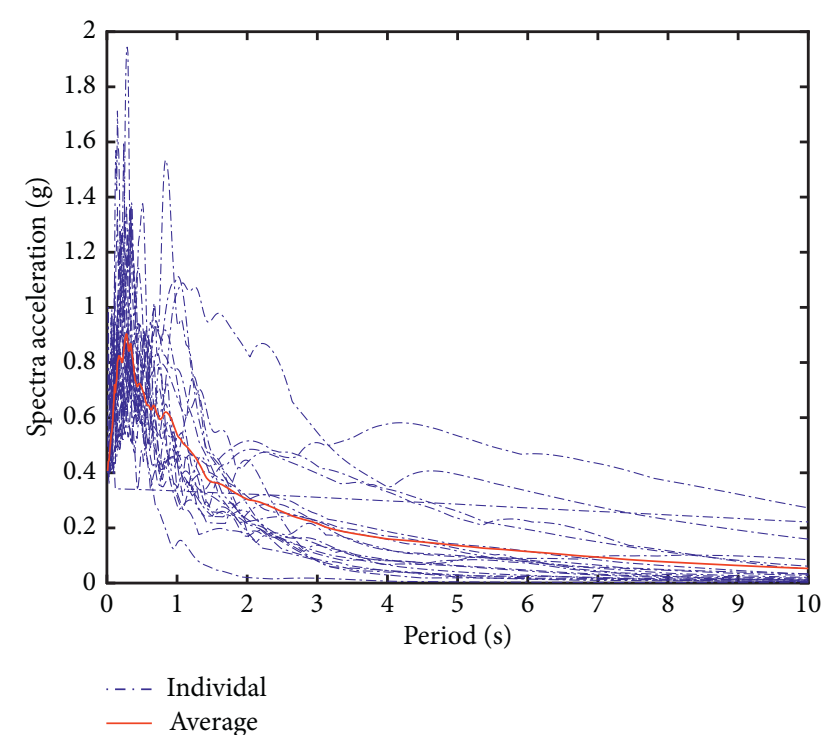

FIgURE 3: Horizontal acceleration response spectrum for $\xi=5 \%$.

characteristic of the isolator changes from pure-softening characteristic to pure-hardening characteristic.

5.3. Effect of Static Equilibrium Position $h_{0}$. The effect of the static equilibrium position $h_{0}$ and vertical eccentricity ratio $e / r$ on ACCX, horizontal displacement $x$, ACCZ, vertical displacement $z$, rotation $\theta$, and rocking moment $T_{c r}$ of the system is displayed in Figure $7(\xi=5 \%, T=1 \mathrm{~s})$. The length of oblique spring is $L=0.5 \mathrm{~m}$. The resulting value of $\gamma$ is 0.87 . $B=9 \mathrm{~m}, H=27 \mathrm{~m}, H_{0}=12 \mathrm{~m} . \xi_{h}=0.2, T_{h}=2 \mathrm{~s}$. Five values of the static equilibrium positions $h_{0}=0.00 \mathrm{~m}$, $h_{0}=0.05 \mathrm{~m}, h_{0}=0.10 \mathrm{~m}, h_{0}=0.15 \mathrm{~m}$, and $h_{0}=0.20 \mathrm{~m}$ are

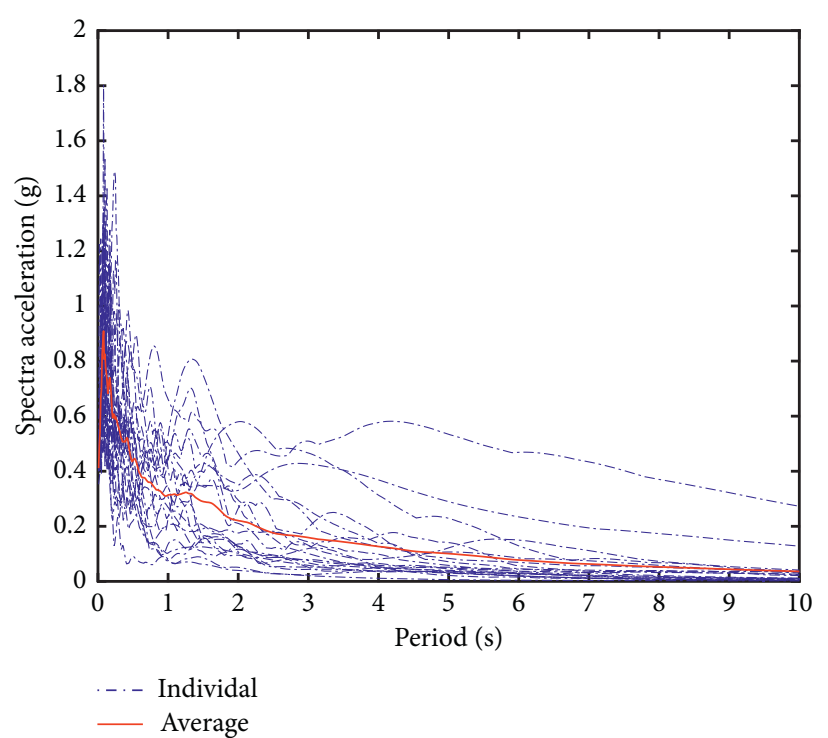

Figure 4: Vertical acceleration response spectrum for $\xi=5 \%$.

selected to study on the impact response of the effect of static equilibrium positions of the vertical seismic isolation bearing on the seismic response of the base-isolated structure.

It can be seen that the ACCX, horizontal displacement $x$, vertical displacement $z$, rotation $\theta$, and rocking moment $T_{c r}$ increase when vertical eccentricity ratio $e / r$ increases. The vertical displacement has a steady trend as vertical eccentricity ratio $e / r$ increases for the static equilibrium positions $h_{0}=0.15 \mathrm{~m}$. When static equilibrium position $h_{0}$ is relatively small, ACCZ is less than 1.0, where the isolator is able to mitigate vibrations efficiently. When static equilibrium position $h_{0}$ is $0.2 \mathrm{~m}$, vertical displacement $z$ can be 


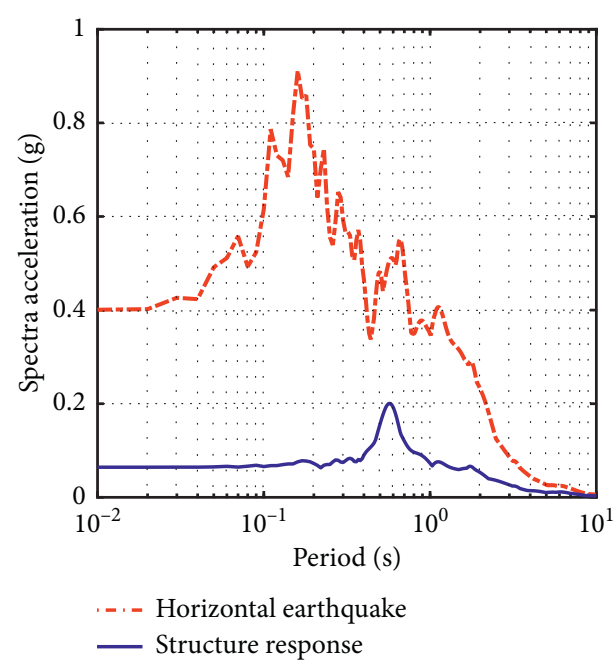

(a)

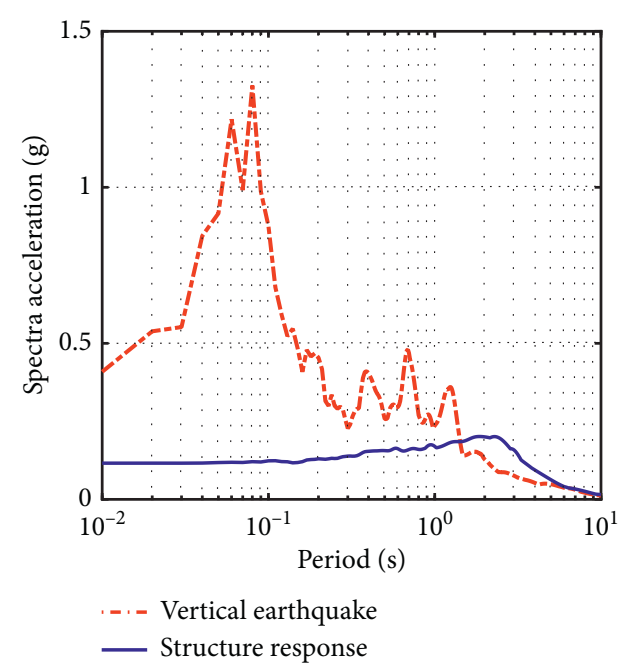

(b)

FIGURE 5: Horizontal and vertical acceleration response spectrum comparison for input NF waves and acceleration response of vertical isolated structure with QZS and VD.

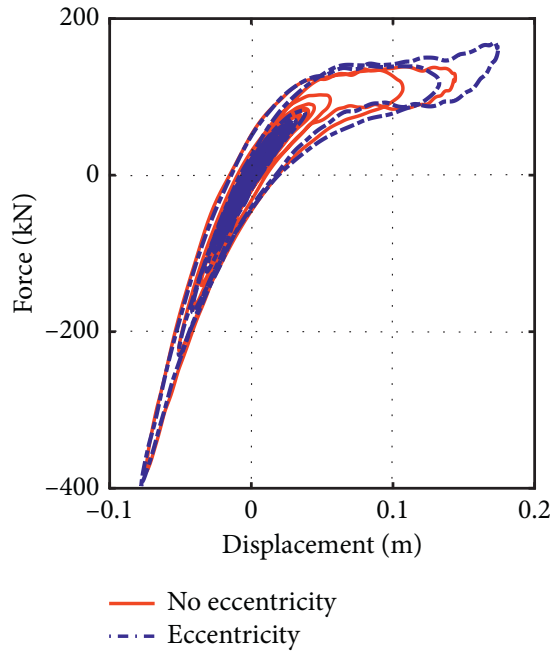

(a)

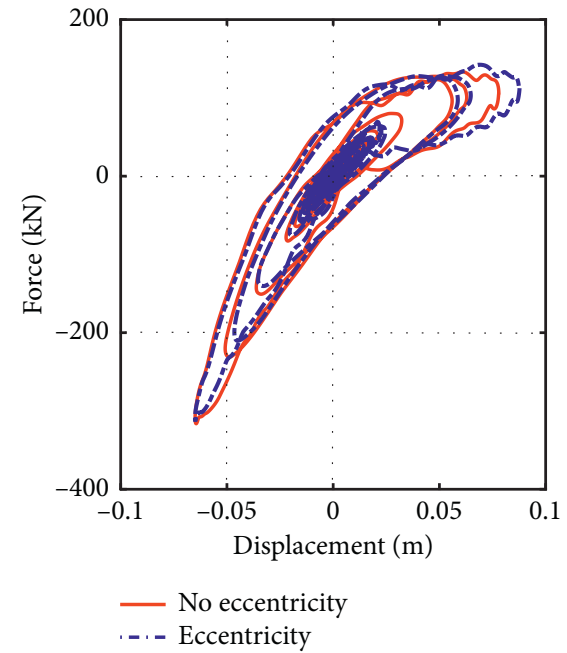

(b)

FIGURE 6: Comparison of vertical force vs. deformation for vertical isolated structure with eccentricity and without eccentricity.

controlled within $0.15 \mathrm{~m}$. It means that increasing static equilibrium position $h_{0}$ can control the vertical displacement responses. The horizontal displacement $x$ and rotation $\theta$ have no evident tendency with the variation of static equilibrium position $h_{0}$.

5.4. Effect of Vertical Period T. Figure 8 presents the ACCX, horizontal displacement $x$, ACCZ, vertical displacement $z$, rotation $\theta$, and rocking moment $T_{c r}$ of the system with fixed damping ratio $\xi=5 \%$ and static equilibrium position $h_{0}=$ $0.05 \mathrm{~m}$ for a different vertical period $T$ and vertical eccentricity ratio $e / r$. The length of oblique spring is $L=0.5 \mathrm{~m}$. The resulting value of $\gamma$ is $0.87 . B=9 \mathrm{~m}, H=27 \mathrm{~m}$, $H_{0}=12 \mathrm{~m} . \xi_{h}=0.2, T_{h}=2 \mathrm{~s}$. It can be observed that ACCZ decreases when vertical period $T$ increases. In contrast, other response parameters increase when vertical period $T$ increases. For a different $T$, the effect of $e / r$ on ACC is insignificant.

5.5. Effect of Damping Ratio $\xi$. Figure 9 shows the ACCX, horizontal displacement $x, \mathrm{ACCZ}$, vertical displacement $z$, rotation $\theta$, and rocking moment $T_{c r}$ of the system with different $\xi$ and $e / r\left(h_{0}=0.1 \mathrm{~m}, T=1 \mathrm{~s}\right)$. The length of oblique spring is $L=0.5 \mathrm{~m}$. The resulting value of $\gamma$ is 0.87 . $B=9 \mathrm{~m}, H=27 \mathrm{~m}, H_{0}=12 \mathrm{~m}$. $\xi_{h}=0.2, T_{h}=2 \mathrm{~s}$. It shows that vertical seismic responses reduce when the vertical damping ratio $\xi$ increases. Although increasing the eccentricity will result in a detrimental effect on seismic isolation, 

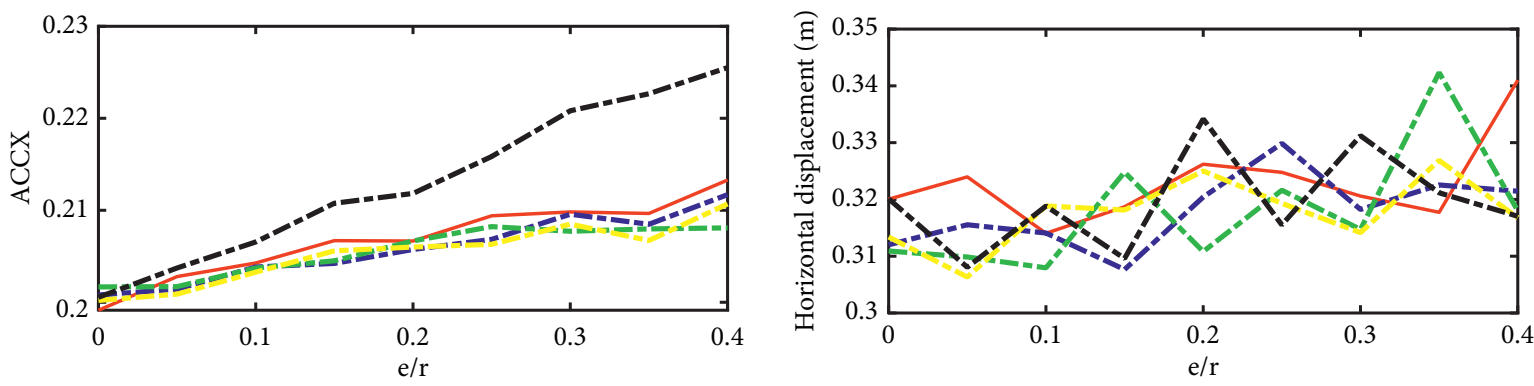

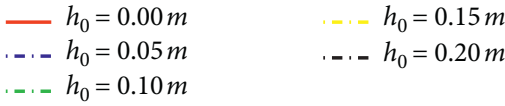

(a)

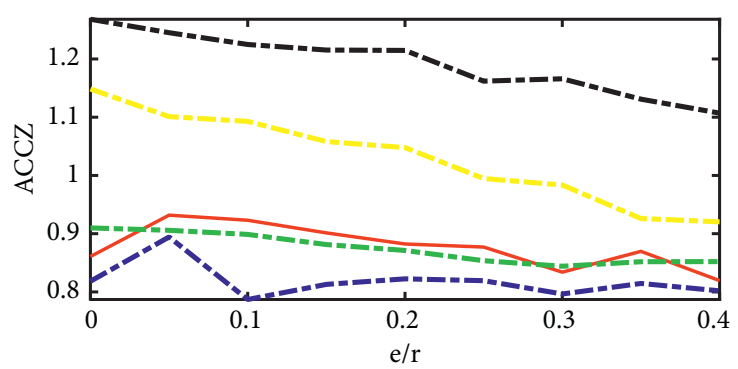

(c)

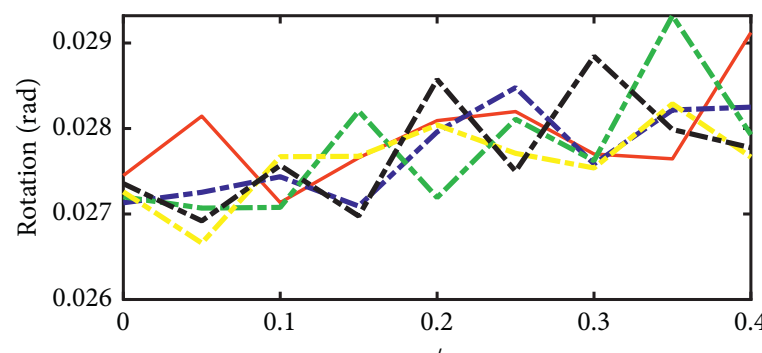

$\mathrm{e} / \mathrm{r}$

$$
\begin{aligned}
& -h_{0}=0.00 \mathrm{~m} \\
& \text { - - } h_{0}=0.05 \mathrm{~m} \\
& \text { - }-h_{0}=0.10 \mathrm{~m} \\
& =h_{0}=0.15 \mathrm{~m} \\
& \text { - - - } h_{0}=0.20 \mathrm{~m}
\end{aligned}
$$

(e)

$$
\begin{aligned}
& -h_{0}=0.00 \mathrm{~m} \\
& \text { - - } h_{0}=0.05 \mathrm{~m} \\
& \text {-. - } h_{0}=0.10 \mathrm{~m} \\
& \begin{aligned}
-h_{0} & =0.15 \mathrm{~m} \\
-\cdots & h_{0}=0.20 \mathrm{~m}
\end{aligned}
\end{aligned}
$$

(b)

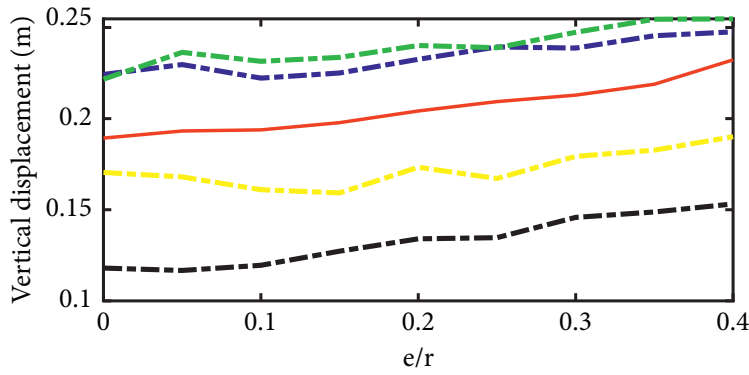

$$
\begin{aligned}
-h_{0} & =0.00 m \\
--h_{0} & =0.05 m \\
--h_{0} & =0.10 m
\end{aligned} \quad-\quad-h_{0}=0.20 m
$$

(d)

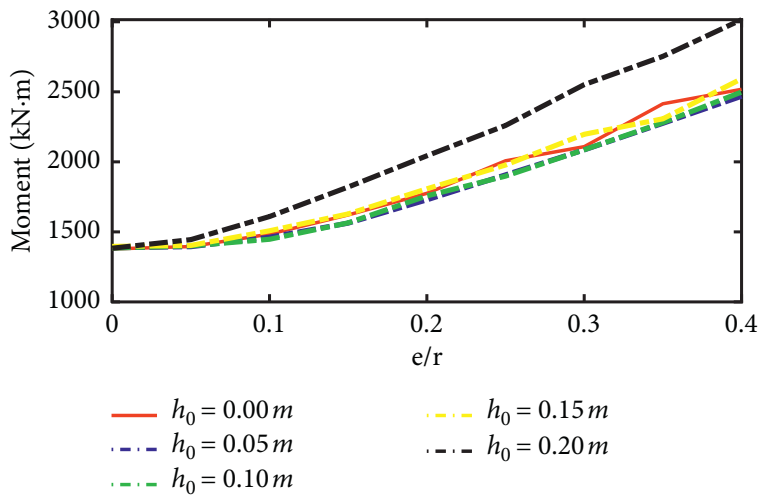

(f)

Figure 7: Peak responses of isolated structure for different $h_{0}$ and $e / r$ and a fixed $\xi=5 \%$. (a) ACC. (b) Vertical displacement. (c) Rotation. (d) Rocking moment.

it is preferable to have relatively high damping to control the response of the system. Significant decrease in ACCZ, vertical displacement $z$, and rocking moment $T_{c r}$ of the system with increase in vertical damping ratios is observed in Figures 9(c), 9(d), and 9(f). The horizontal displacement $x$ and rotation $\theta$ have no evident tendency with the variation of vertical damping ratio $\xi$. Rocking moment $T_{c r}$ increases with increasing $e / r$. ACCZ and vertical displacement $z$ can keep a steady variation with increasing $e / r$. It indicates that the effects of rocking coupling on the vertical acceleration response of a base-isolated structure is insignificant for different $e / r$. For all cases of different vertical damping ratio $\xi$, the ACCZ is less than 1. This means that adding vertical dampers helps to control vertical seismic responses and rotation response.

\section{Comparison Analysis}

In order to compare the effect of rocking on vibration control of the vertical isolated system with QZS and VD and structure with rubber bearing, we consider isolating the same mass under the same external excitation conditions. Here, rubber bearings are used for the system. The vertical stiffness $k_{v b}$ is $1683.2 \mathrm{kN} / \mathrm{mm}$. The vertical nature period of 


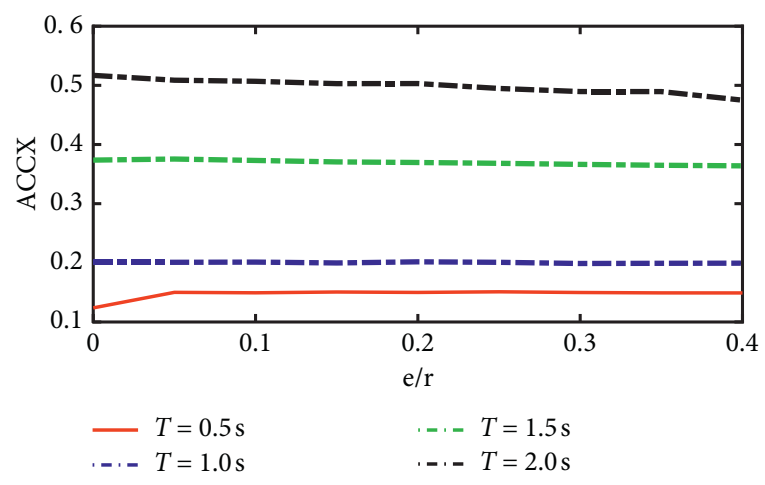

(a)

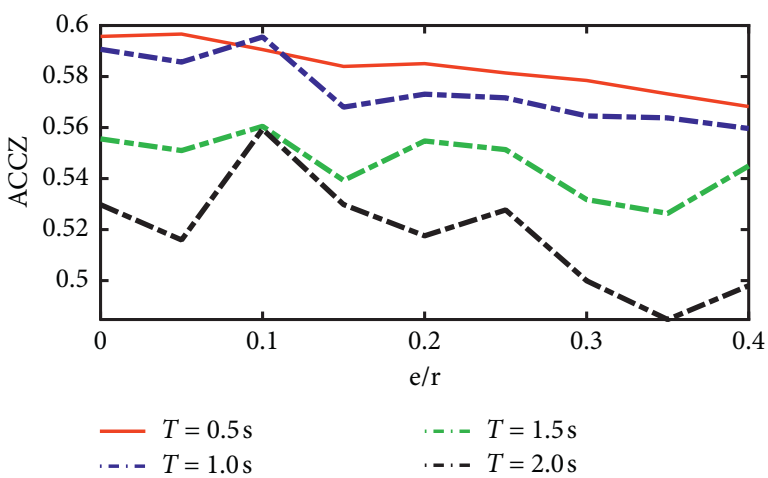

(c)

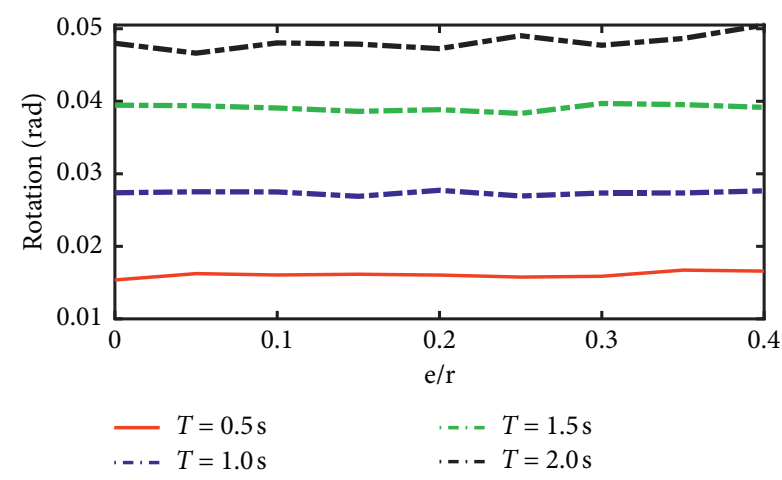

(e)

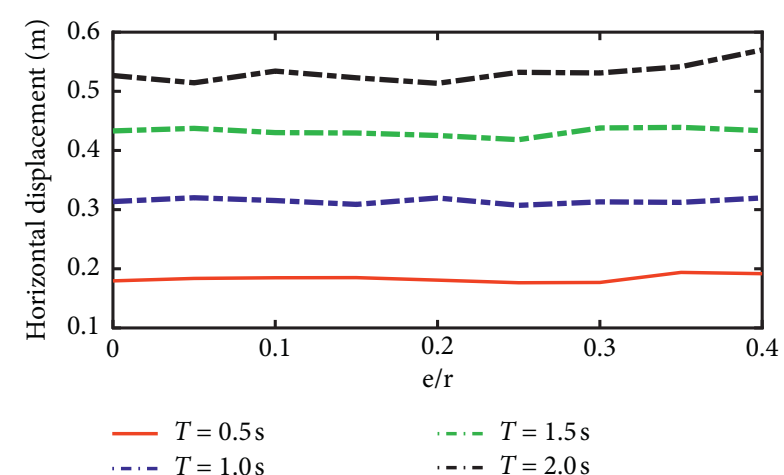

(b)

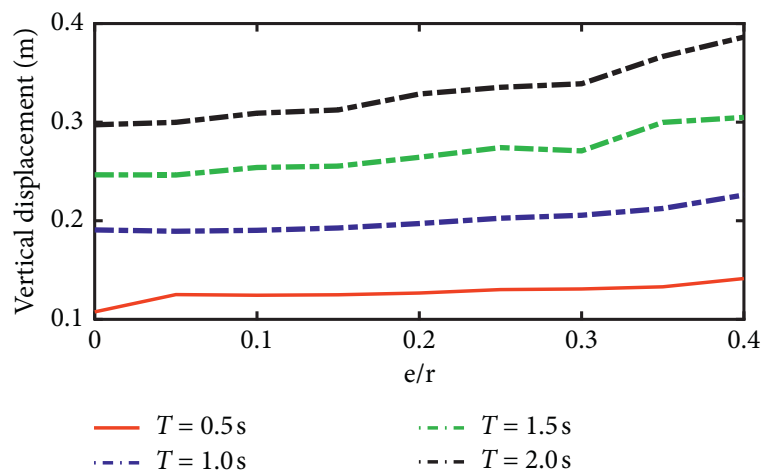

(d)

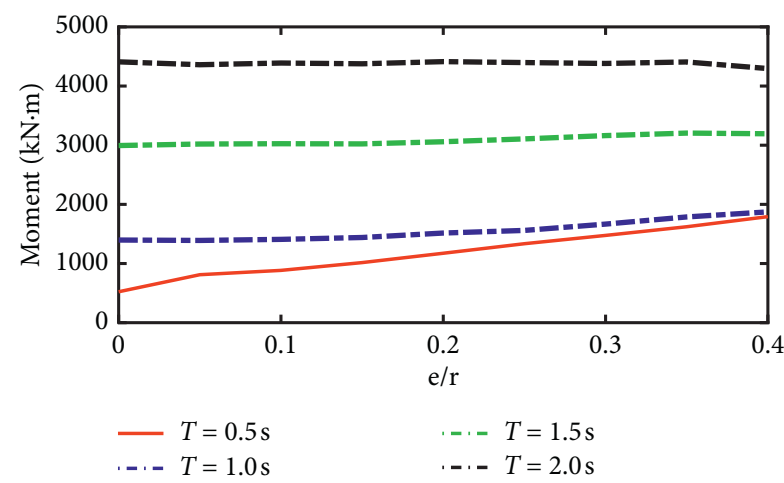

(f)

Figure 8: Peak responses of isolated structure for different $T$ and $e / r$ : (a) ACC. (b) Vertical displacement. (c) Rotation. (d) Rocking moment.

the seismic isolated system without QZS and VD is $0.068 \mathrm{~s}$. The equation of motion of the same mass system with rubber bearing is

$$
\left[\begin{array}{cc}
m & 0 \\
0 & m r^{2}
\end{array}\right]\left\{\begin{array}{l}
\ddot{z}_{0} \\
\ddot{\theta}_{0}
\end{array}\right\}+\left[\begin{array}{cc}
k_{v b} & k_{v b} e \\
k_{v b} e & k_{v b} e^{2}
\end{array}\right]\left\{\begin{array}{c}
z_{0} \\
\theta_{0}
\end{array}\right\}+[C]\left\{\begin{array}{c}
\dot{z}_{0} \\
\dot{\theta}_{0}
\end{array}\right\}=-\left[\begin{array}{cc}
m & 0 \\
0 & m r^{2}
\end{array}\right]\left\{\begin{array}{c}
\ddot{z}_{g} \\
0
\end{array}\right\} .
$$

To compare the performance of the vertical system and fixed structure supported on rubber bearing, the acceleration and rocking moment reduction coefficient are as evaluation indexes to represent the isolation effect as follows: 


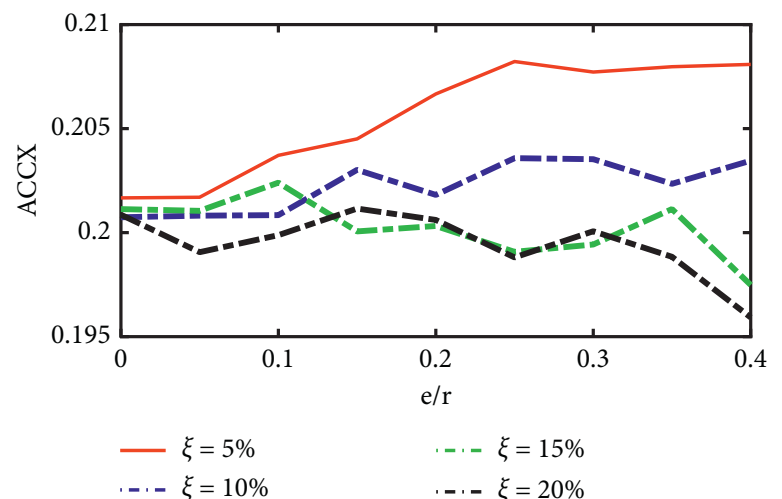

(a)

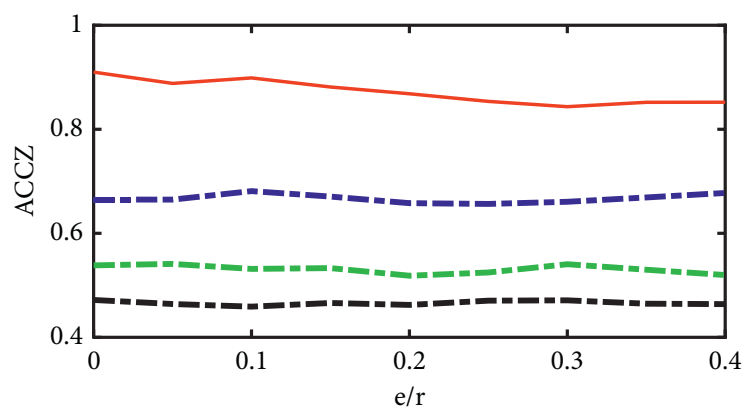

$$
-\xi=5 \%
$$$$
\text { .-. } \xi=10 \%
$$

- - $\xi=15 \%$

- - $\xi=20 \%$

(c)

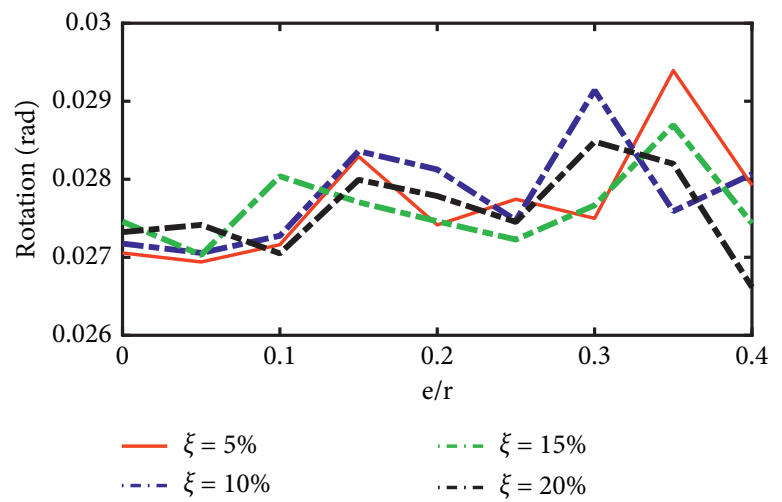

(e)

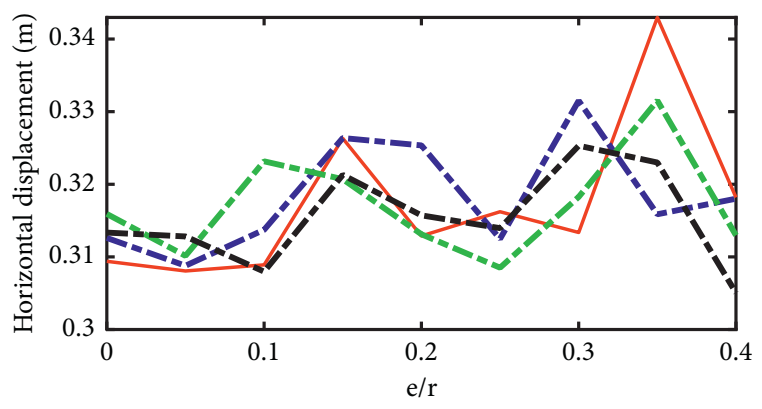

$-\xi=5 \%$

. - - $\xi=15 \%$

... $\xi=10 \%$

... $\xi=20 \%$

(b)

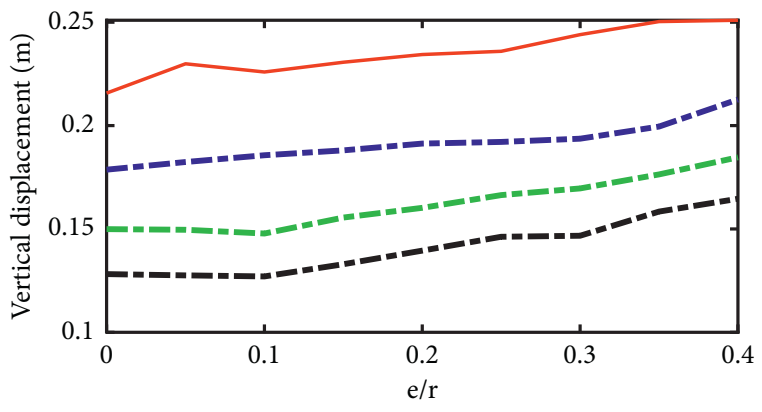

$-\xi=5 \%$

- $-=\xi=15 \%$

- $\xi=10 \%$

- - $\xi=20 \%$

(d)

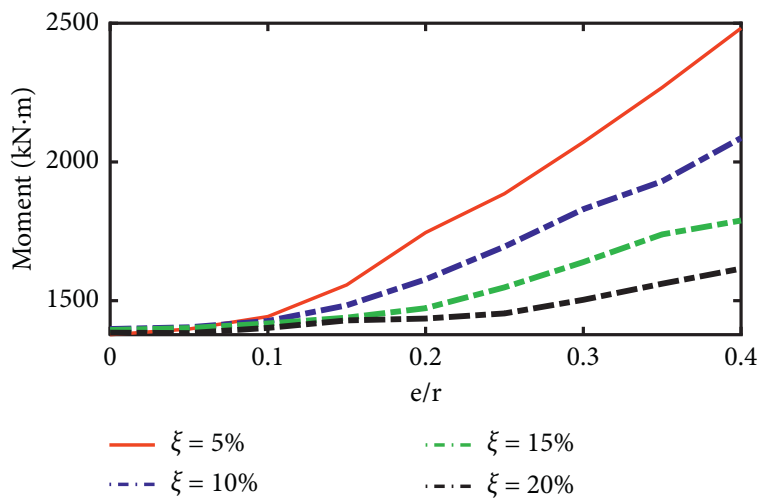

(f)

FIGURE 9: Peak responses of isolated structure for different $\xi$ and $e / r$ and a fixed $h_{0}=0.1 \mathrm{~m}$. (a) ACC. (b) Vertical displacement. (c) Rotation. (d) Rocking moment.

$$
\begin{gathered}
\eta=\frac{\max (|\ddot{z}|)}{\max \left(\left|\ddot{z}_{0}\right|\right)}, \\
\tau=\frac{\max \left(\left|T_{c r}\right|\right)}{\max \left(\left|T_{c r 0}\right|\right)},
\end{gathered}
$$

where $T_{c r 0}$ is rocking moment of the structure without vertical isolation bearing.

Figure 10 shows the comparison of the acceleration reduction coefficient of the vertical isolated system with QZS and $\mathrm{VD}$ in comparison with the structure using rubber bearing. From Figure 10(a), it can be seen that the vertical isolated bearing can reduce the acceleration, about $80 \%$ and $89 \%$ for vertical period $T=0.5 \mathrm{~s}$ and $2.0 \mathrm{~s}$, respectively, in comparison with the structure using rubber bearing. It indicates that although there is a vertical eccentricity in the structure, the vertical bearing using QZS and VD can decrease the peak absolute vertical acceleration of the seismic isolated structure.

In Figure 10(b), the vertical isolated bearing can reduce the rocking moment, about $81 \%$ and $89 \%$ for vertical period $T=0.5 \mathrm{~s}$ and $1.0 \mathrm{~s}$, respectively, in comparison with the structure using rubber bearing. This example system clearly 


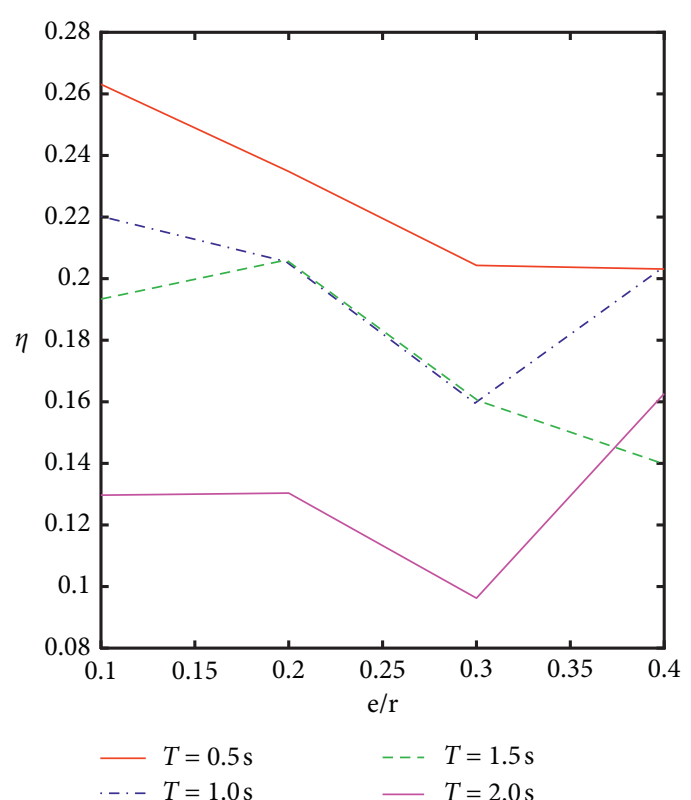

(a)

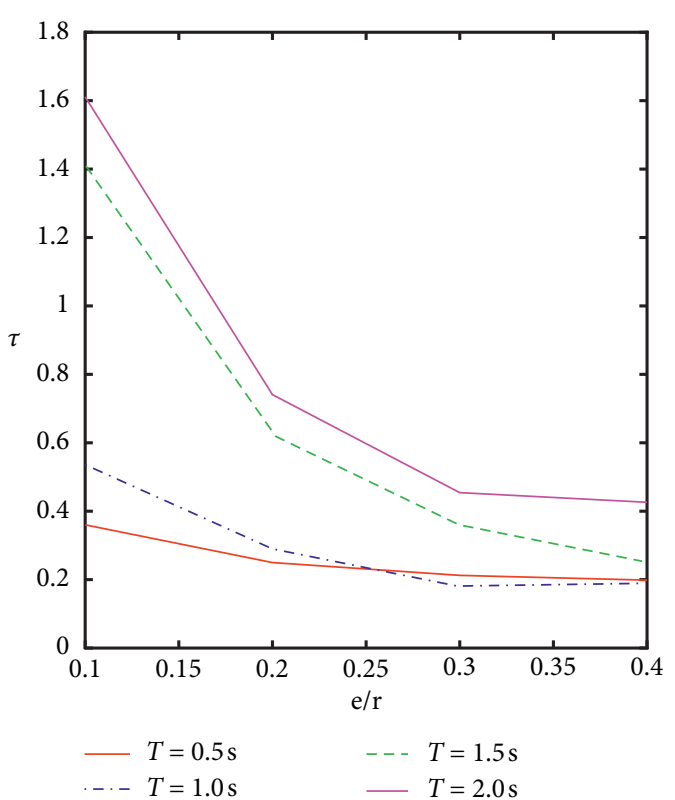

(b)

Figure 10: Comparison of response reduction of isolated structure for different $T$ and $e / r$ and a fixed $h_{0}=0.1 \mathrm{~m}$. (a) $\eta$; (b) $\tau$.

illustrates the effectiveness of the vertical isolated system with QZS and VD in comparison with the structure using rubber bearing in reducing rocking response of isolated structures.

\section{Conclusions}

Nonlinear time history analyses were performed to investigate the rocking responses and isolation effects of the seismic isolated system with QZS and VD under NF horizontal and vertical ground motions. From the results presented in this paper, the following conclusions are drawn:

(1) The effect of static equilibrium position, vertical period, and damping ratio on horizontal-verticalrocking response for the vertical seismic isolated system with QZS and VD under NF horizontal and vertical ground motions is significant. It needs to be considered in the analysis of vertical isolated structure with vertical eccentricity.

(2) The effect of eccentricity ratio on acceleration responses of the vertical seismic isolated system with QZS and VD is insignificant.

(3) The vertical seismic isolated system with QZS and VD can provide reasonable isolation effects to control NF vertical earthquakes compared with the system supported on rubber bearings.

\section{Abbreviations}

m: $\quad$ Mass of a lumped parameter model for a seismic isolated structure

L: $\quad$ Length of the oblique spring

a: $\quad$ Horizontal projection length of the oblique spring $k_{h}, c_{h}$ : Horizontal spring stiffness and damping

$k_{v}, c_{v}$ : Vertical spring stiffness and damping Coefficient

$x$ : $\quad$ Horizontal displacement of a seismic isolated structure

$z: \quad$ Vertical displacement of a seismic isolated structure

F: $\quad$ Vertical force applied to the mass of a seismic isolated structure

$k$ : $\quad$ The oblique spring stiffness

$\beta=k / k_{v}$ : The ratio of spring stiffness

$\gamma=a / L$ : The configurative parameter of the system

$\ddot{x}_{g}$ : Horizontal seismic acceleration.

$\ddot{z}_{g}$ : $\quad$ Vertical seismic acceleration.

$B: \quad$ Width of the system

$H$ : $\quad$ Height of the system

$H_{0}$ : Constant elevation below the CM of the building

$r$ : $\quad$ Radius of gyration of the rigid block.

\section{Data Availability}

The data used to support the findings of this study are available from the corresponding author upon request.

\section{Conflicts of Interest}

The authors declare that there are no conflicts of interest regarding the publication of this paper.

\section{Acknowledgments}

The authors gratefully acknowledge the financial support of National Natural Science Foundation of China (No. 51808467 and 51508414), Yunnan Agriculture Foundation Fund Project (No. 2017FG001-097), Doctor Start-up Fund of 
Southwest Forestry University, and Yunnan Postdoctoral Fund (2018).

\section{References}

[1] S. Furukawa, E. Sato, Y. Shi, T. Becker, and M. Nakashima, "Full-scale shaking table test of a base-isolated medical facility subjected to vertical motions," Earthquake Engineering \& Structural Dynamics, vol. 42, no. 13, pp. 1931-1949, 2013.

[2] J. C. Guzman Pujols and K. L. Ryan, "Computational simulation of slab vibration and horizontal-vertical coupling in a full-scale test bed subjected to 3D shaking at E-defense," Earthquake Engineering \& Structural Dynamics, vol. 47, no. 2, pp. 438-459, 2018.

[3] A. J. Papazoglou and A. S. Elnashai, "Analytical and field evidence of the damaging effect of vertical earthquake ground motion," Earthquake Engineering \& Structural Dynamics, vol. 25, no. 10, pp. 1109-1137, 1996.

[4] M. Morishita, K. Inoue, and T. Fujita, "Development of threedimensional seismic isolation systems for fast reactor application," Journal of JAEE, vol. 4, no. 3, pp. 305-310, 2004.

[5] T. Tomizawa, O. Takahashi, H. Aida et al., "Vibration test in a building named "chisuikan" using three-dimensional seismic isolation system," in Proceedings of the The 15th World Conference on Earthquake Engineering, Pittsburgh, PA, USA, May 2012.

[6] A. Carrella, M. J. Brennan, and T. P. Waters, "Static analysis of a passive vibration isolator with quasi-zero-stiffness characteristic," Journal of Sound and Vibration, vol. 301, no. 3-5, pp. 678-689, 2007.

[7] Y. Araki, K. Kimura, T. Asai, T. Masui, T. Omori, and R. Kainuma, "Integrated mechanical and material design of quasi-zero-stiffness vibration isolator with superelastic $\mathrm{Cu}$-AlMn shape memory alloy bars," Journal of Sound and Vibration, vol. 358, pp. 74-83, 2015.

[8] L. Di Sarno, E. Chioccarelli, and E. Cosenza, "Seismic response analysis of an irregular base isolated building," Bulletin of Earthquake Engineering, vol. 9, no. 5, pp. 1673-1702, 2011.

[9] M. Fallahian, F. Khoshnoudian, and V. Loghman, "Torsionally seismic behavior of triple concave friction pendulum bearing," Advances in Structural Engineering, vol. 18, no. 12, pp. 2151-2166, 2015.

[10] F. Mazza, "Seismic demand of base-isolated irregular structures subjected to pulse-type earthquakes," Soil Dynamics and Earthquake Engineering, vol. 108, pp. 111-129, 2018.

[11] G. Liu, J. Chen, M. Xiao, and Y. Yang, "Dynamic response simulation of lining structure for tunnel portal section under seismic load," Shock and Vibration, vol. 2018, Article ID 9149721, 12 pages, 2018. 